\title{
Rancang Bangun Sistem Informasi Manajemen Keuangan Sekolah
}

\author{
Design of School Financial Management Information System
}

\author{
${ }^{1}$ Ahmad Habib, ${ }^{2}$ Berlian Al Kindhi \\ ${ }^{1,2}$ Teknik Informatika, Universitas 17 Agustus Surabaya \\ ${ }^{1,2}$ Surabaya, Indonesia \\ E-mail: ${ }^{1}$ habib@untag-sby.ac.id, ${ }^{2}$ berlian.alkindhi@untag-sby.ac.id
}

\begin{abstract}
Abstrak - Proses pengolahan data keuangan sekolah jika dilakukan secara manual maka hasilnya kurang efektif. Sehingga diperlukan sistem informasi manajemen data keuangan untuk meningkatkan kualitas pelayanan kepada siswa dan mempercepat kinerja pegawai disekolah. Diharapkan sistem ini dapat meningkatkan kinerja pegawai atau guru yang ada disekolah termasuk ketua dilembaga dalam mengambil keputusan. Tujuan penelitian ini adalah membuat sistem informasi manajemen keuangan sekolah yang dirancang dan dibangun dengan mengunakan bahasa pemrograman PHP dan database MySQL dengan begitu maka dapat mengolah data-data keuangan sekolah seperti pembayaran spp dan pembuatan laporan keuangan dilakukan dengan efisisen dan efektif. Dalam penelitian ini, penulis menggunakan dua buah metode, yaitu metode pengumpulan data dan metode pengembangan sistem. Untuk metode pengumpulan data, penulis menggunakan tiga cara, yaitu observasi, interview dan studi pustaka sedangan untuk pengembangan sistem metode yang kami terapkan adalah metode incremental yang memilik 5 tahapan, yaitu communication, planning, modelling, construction, dan deployment.
\end{abstract}

Kata Kunci-system informasi, manajemen keuangan, keuangan sekolah, metode incremental

Abstract-School financial data processing if done manually then the result is less effective. So required financial information management information system to improve the quality of service to students and accelerate the performance of employees in school. It is expected that this system can improve the performance of employees or teachers in school including chairman institutionalized in making decisions. The purpose of this study is to make school financial management information system designed and built by using PHP programming language and MySQL database so that it can process the school finance data such as tuition fee payment and making financial reports done efficiently and effectively. In this study, the author uses two methods, namely data collection methods and methods of system development. For data collection method, we use three way, that is observation, interview and study of library for development of system method used by writer that is incremental method having 5 stages, that is communication, planning, modeling, construction, deployment.

Keywords-Information System, Financial Management, Financial School, Incremental Methods 


\section{PENDAHULUAN}

Manajemen pengolahan data keuangan sekolah masih ada yang menggunakan system manual dan dianggap tidak efisien. Untuk membantu proses pengolahan data-data keuangan tersebut diperlukan adanya sebuah sistemyang terkomputerisasi yang dapat menghasilkan informasi akurat tepat waktu dan relevan. Kebutuhan akan sistem informasi keuangan yang lebih baik ini sudah tidak dapat ditunda lagi. Keberadaan fasilitas pendukung seperti komputer belum dimanfaatkan secara optimal.

Seiring dengan kemajuan teknologi informasi yang membutuhkan informasi disajikan secara cepat dan akurat. Tentunya membutuhkan suatu alat media atau sistem yang dapat mengolah data secara efektif. Jika suatu instansi atau lembaga sekolah masih menggunakan cara manual akan kesulitan atau lama dalam mengolah data keuangan tersebut. Berdasarkan permasalahan tersebut sebaiknya dibuat suatu sistem yang dapat memproses segala data keuangan. Sehingga proses pengolahan data dapat dilakukan dengan lebih mudah serta meminimalkan timbulnya kesalahan.

Dengan adanya kondisi tersebut maka akan dijadikan sebagai objek penelitian dengan judul "Rancang Bangun Sistem Informasi Manajemen Keuangan Sekolah Dengan bahasa pemrograman PHP dan database MySQL". Diharapkan dengan adanya sistem yang terkomputerisasi ini dapat membantu mempermudah proses pengolahan data-data keuangan sehingga dapat menghasilkan informasi yang akurat, tepat waktu dan relevan.

Tujuan penelitian ini adalah untuk mengatasi kelemahan sistem yang ada disekolah atau lembaga dengan cara membuat sistem informasi pengelolahan keuangan untuk sekolah yang baik dengan mengunakan bahasa pemrograman PHP dan database MySQL sehingga proses administrasi keuangan menjadi lebih praktis dan akurat. Hasil dari pembangunan aplikasi ini mampu meminimalisir kelemahan sistem keuangan dan membuat kinerja bagian keuangan menjadi lebih mudah, cepat dan akurat.

\section{LITERATUR}

Sistem informasi adalah suatu sistem yang mereprensetasikan proses bisnis suatu instansi atau perusahaan berdasarkan struktur organisasi instansi atau perusahaan tersebut.[1] [2] [3] [4].Dimana setiap bagian dari proses bisnis tersebut dijalankan oleh bagian terkecil dari system informasi yaitu sub modul [5] [6] [7]. Sehingga pembangunan suatu system informasi hendaknya didasarkan pada pola proses bisnis dari instansi atau perusahaan tersebut [8]. 
INTENSIF, Vol.2 No.2 August 2018

ISSN: 2580-409X (Print) / 2549-6824 (Online)

Website: http//ojs.unpkediri.ac.id/index.php/intensif

Keberhasilan penerapan system informasi di dasarkan pada minimnya tindakan resistensi oleh pengguna terhadap system informasi. Selain itu, dengan semakin bertambahnya nilai bisnis suatu instansi atau perusahaan dikarenakan penerapan sistem informasi merupakan salah satu indicator suksesnya penerapan sistem informasi [9] [10].

Setiap bagian dari sub modul akan digabungkan menjadi suatu kesatuan yang disebut dengan sistem informasi, dengan kata lain, sistem informasi adalah implementasi proses bisnis ke dalam suatu aplikasi [11]. Suatu sistem informasi harus memiliki suatu kemampuan untuk menggabungkan setiap tahap proses bisnis menjadi integrase antar modul [12] [13].

Transaksi yang sebelumnya dilakukan secacra manual akan dilakukan secara sistemisasi, sehingga instansi/perusahaan dapat menjalankan proses bisnis lebih efektif dan efisien baik dari segi waktu, tenaga, dan biaya [14] [15]. Manajemen keuangan merupakan hal yang penting dalam menjalankan proses bisnis, oleh karena itu dibutuhkan suatu sistem informasi yang meningkatkan elektabilitas dari instansi/perusahaan tersebut [16] [17].

\section{METODOLOGI}

Dalam penelitian ini, penulis menggunakan dua buah metode, yaitu metode pengumpulan data dan metode pengembangan sistem. Dalam metode pengumpulan data, penulis menggunakan tiga metode, yaitu observasi, interview, dan studi pustaka. Observasi ini digunakan untuk mengetahui keadaan yang berlangsung secara detail dengan melakukan survey langsung ke lokasi untuk mengetahui kondisi real saat ini. Interview adalah proses penggalian informasi secara langsung dengan orang yang bersangkutan, sehingga akan didapatkan data yang relevan.

Kami menerapkan metode incremental dalam pengembangan system dengan 5 tahapan, yaitu communication, planning, modelling, construction, deployment. Communication adalah bertemu dengan user untuk mendefinisikan tujuan - tujuan umum serta syarat - syarat untuk pembuatan perangkat lunak. Planning adalah membuat jadwal - jadwal yang akan digunakan sebagai acuan untuk membuat perangkat lunak. Modeling adalah membuat model, yakni dengan menganalisa dan mendesain aplikasi yang akan dibuat. Construction adalah membuat desain yang sudah direncanakan menjadi kode - kode program serta desain GUI yang nantinya akan menjadi perangkat lunak serta melakukan testing. Serta Deployment, yaitu aplikasi yang telah jadi kemudian diantarkan kepada user untuk digunakan agar didapatkan feedback dari user. 
INTENSIF, Vol.2 No.2 August 2018

ISSN: 2580-409X (Print) / 2549-6824 (Online)

Website: http://ojs.unpkediri.ac.id/index.php/intensif

Berdasarkan teori pendukung yang telah diuraikan sebelumnya makarancang bangun sistem informasi manajemen keuangan sekolah dapat disusun dalam bentuk context diagram, data flow diagram, entity relantionship diagram, mapping diagram. Sedangkan untuk tabel yang digunakan untuk menyimpan data sistem digambarkan dalam database sistem.Berdasarkan penelitian terdahulu dan teori pendukungnya, maka secara garis besar rancang bangun sistem informasi manajemen keuangan sekolah dapat disusun dalam bentuk diagram kontek seperti Gambar 1.Context diagram adalah model atau pola yang menggambarkan interaksi sistem dengan entitas luar yaitu admin, kepala sekolah, siswa. Admin memiliki hak penuh terhadap sistem dan manajemen data, seperti insert, update, delete.

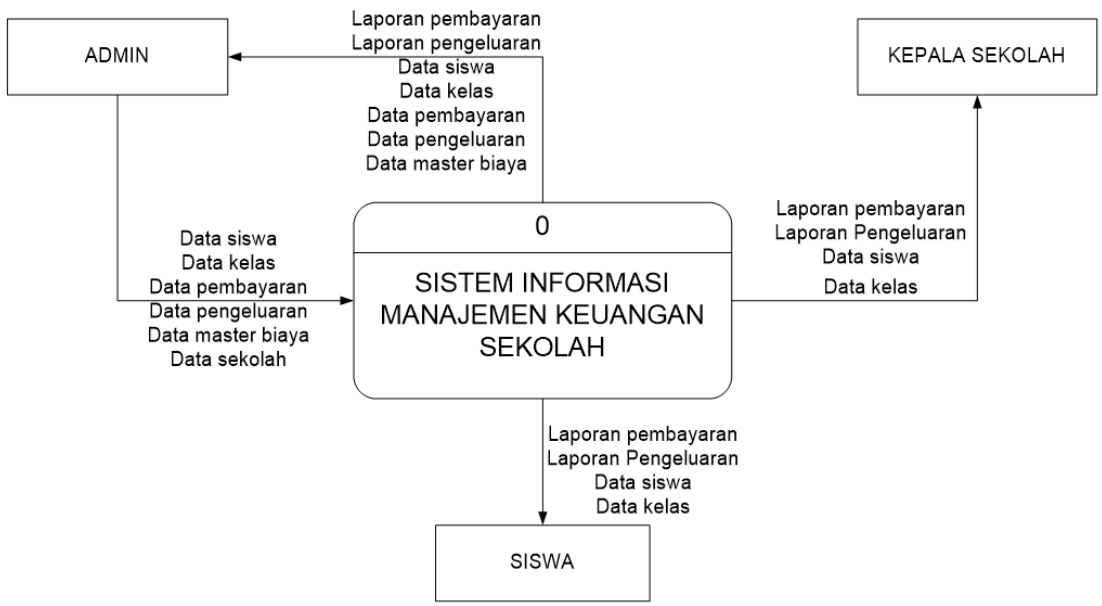

\section{Gambar 1. DIAGRAM KONTEKS SISTEM INFORM ASI MANAJEMEN KEUANGAN SEKOLAH}

Data Flow Diagram (DFD) adalah gambaran dari sistem secara keseluruhan. DFD menjelaskan sistematik logika penggabungan antar modul hingga membentuk sebuah sistem tanpa mempelajari ruang penyimpanannya. DFD Level 1 sistem informasi manajemen keuangan sekolah seperti pada Gambar 2 dibawah ini. 
INTENSIF, Vol.2 No.2 August 2018

ISSN: 2580-409X (Print) / 2549-6824 (Online)

Website: http//ojs.unpkediri.ac.id/index.php/intensif

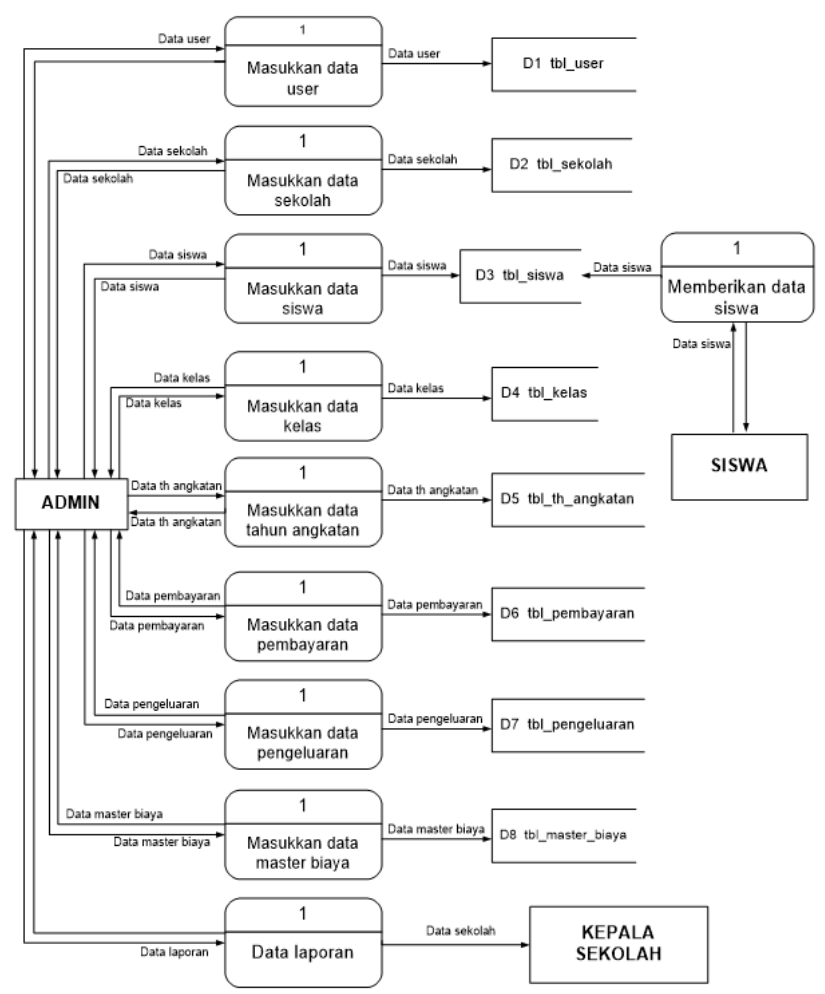

Gambar 2. DFD LEVEL 1 SISTEM INFORM ASI M ANAJEMEN KEUANGAN SEKOLAH

DFD level 2 proses pembayaran di ambil dari tabel tbl_siswa, tabel tbl_kelas dan tabel tbl_master_biaya. Kemudian disimpan ditabel tbl_pembayaran dan di teruskan menjadi laporan yang disampaikan kepada kepala sekolah dan siswa seperti Gambar 3 dibawah ini.

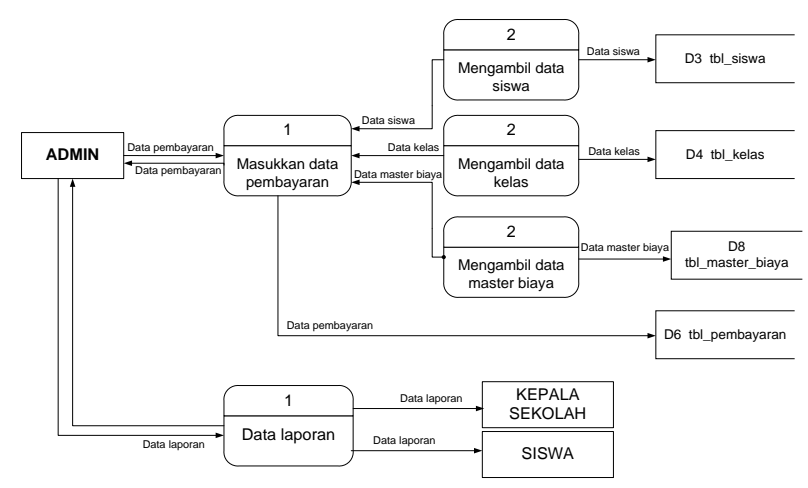

Gambar 3. DiAgram LeVEl 2 PROSES PEMBAyARAN

DFD level 2 proses pengeluaran diambil dari tabel tbl_master_biaya, kemudian di simpan di tabel tbl_pengeluaran dan diteruskan menjadi laporan yang disampaikan kepada kepala sekolah dan siswa seperti nampak pada Gambar 4 dibawah. 
INTENSIF, Vol.2 No.2 August 2018

ISSN: 2580-409X (Print) / 2549-6824 (Online)

Website: http://ojs.unpkediri.ac.id/index.php/intens if

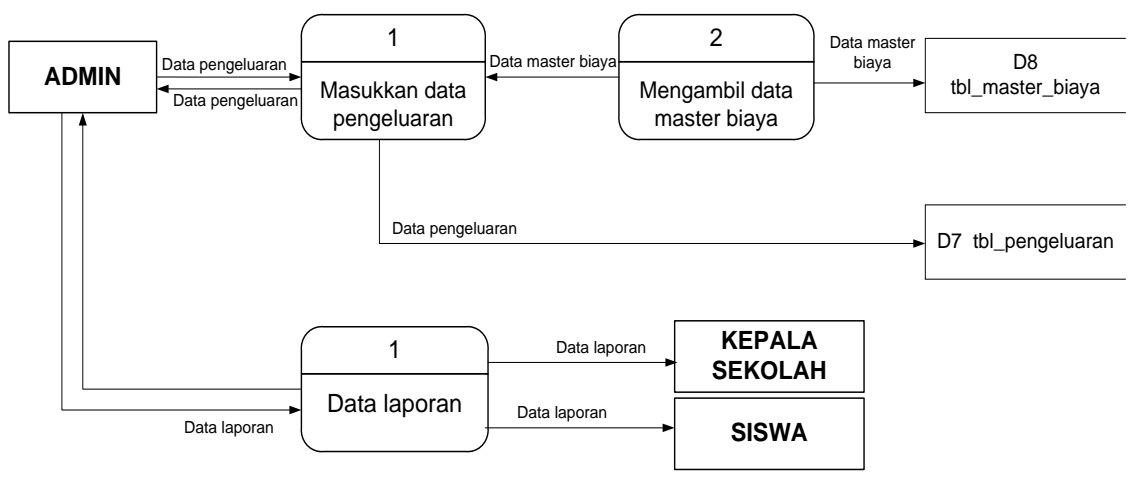

Gambar 4. DFD LeVEl 2 PRoses Pengeluaran

Entity Relationship Diagram (ERD) adalah sebuah model yang merepresentasikan data sistem dengan sejumlah entitas dan relationship. Entitas merupakan obyek tertentu dalam sebuah sistem. Relationship adalah sebuah keterhubungan antara obyek satu dengan banyak obyek lainnya. Entity relationship diagram dari sistem informasi manajemen keuangan sekolah dirancang seperti Gambar 5 dibawah ini.

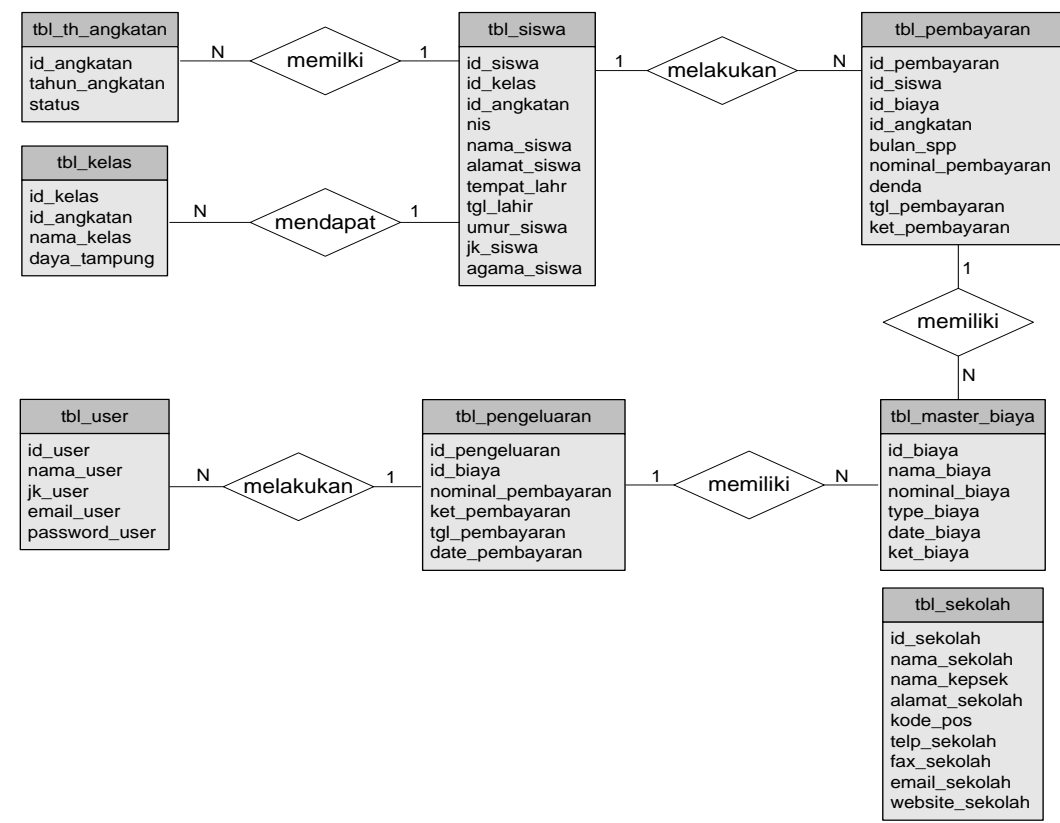

Gambar 5. ERD SISTEM INFORMASI MANAJEMEN KEUANGAN SEKOLAH

Pemetaan data adalah proses menciptakan pemetaan elemen data antara dua model data yang berbeda. Pemetaan data digunakan sebagai langkah awal untuk berbagai tugas interasi data seperti Gambar 6 dibawah ini. 
INTENSIF, Vol.2 No.2 August 2018

ISSN: 2580-409X (Print) / 2549-6824 (Online)

Website: http//ojs.unpkediri.ac.id/index.php/intensif

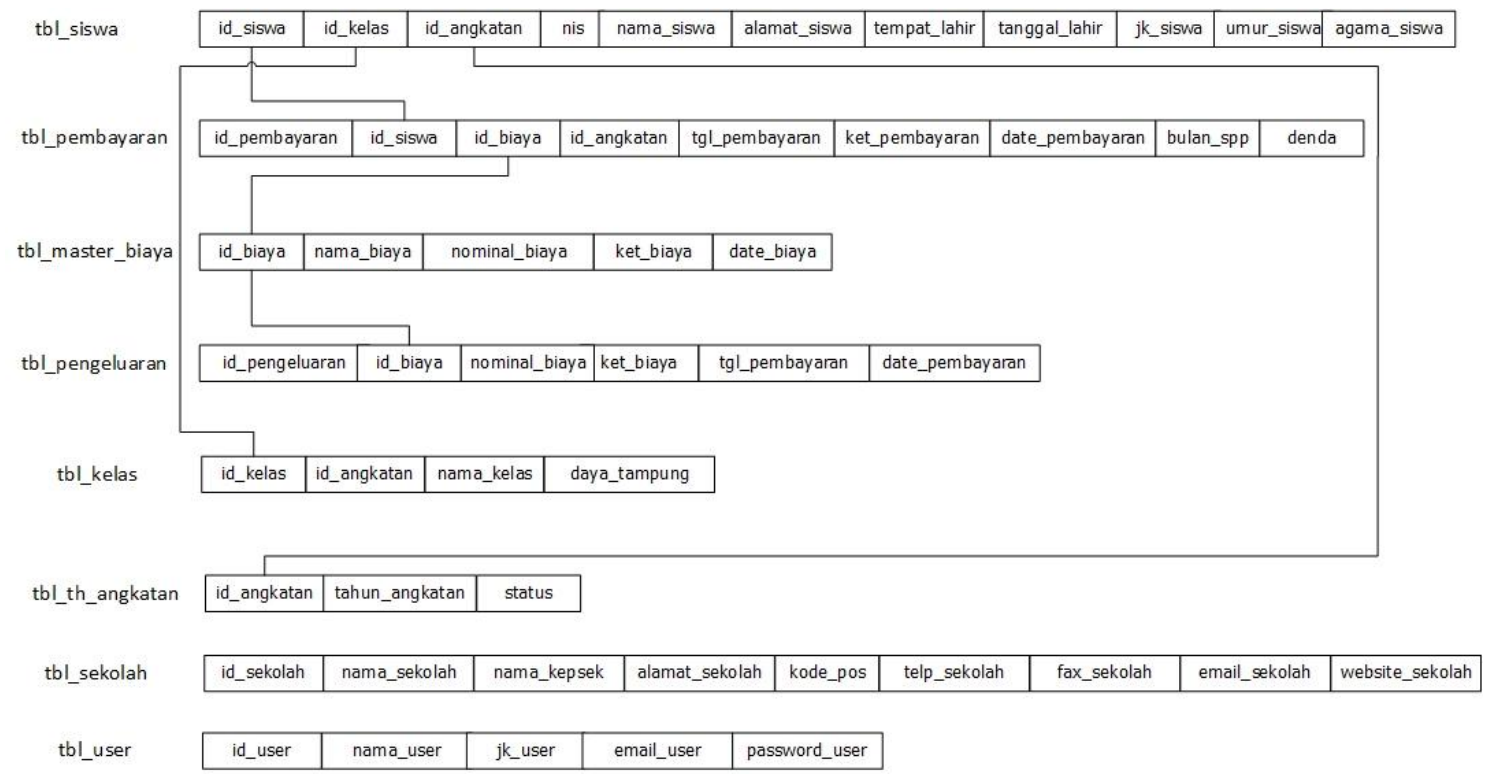

Gambar 6. MAPPING DATABASE

\section{HASIL DAN PEMBAHASAN}

Tahap implementasi program bertujuan mengubah hasil dari rancangan sistem menjadi sistem secara nyata yang siap untuk digunakan. Pertama kali perangkat lunak ini dijalankan sebelum masuk ke sistem utama atau dashboard akan mucul tampilan login dahulu sebagai pengaman terhadap hak akses pengguna seperti Gambar 7 bawah ini.

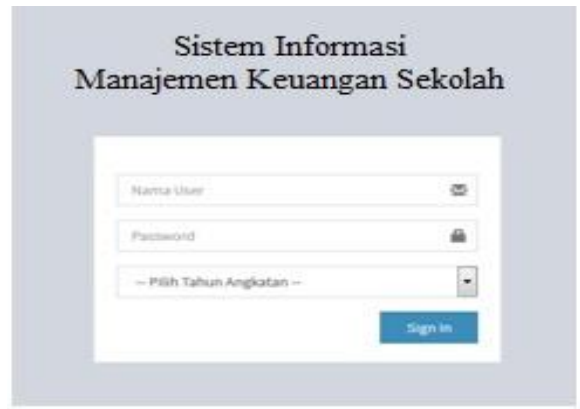

Gambar 7. MENU LOGIN

Pada menu utama atau dashboard dibawah ini ada tiga grup katagori, yaitu nama sistem, status staff tu yang sedang login, dan menu yang ada di bagian samping. Untuk data menu yang di tampilkan yaitu menu pembayaran, menu pengeluaran, menu data siswa, menu data kelas, menu data sekolah, menu data tahun angkatan, menu data master biaya, dan laporan. Hal ini dapat dilihat pada Gambar 8 . 
INTENSIF, Vol.2 No.2 August 2018

ISSN: 2580-409X (Print) / 2549-6824 (Online)

Website: http://ojs.unpkediri.ac.id/index.php/intensif

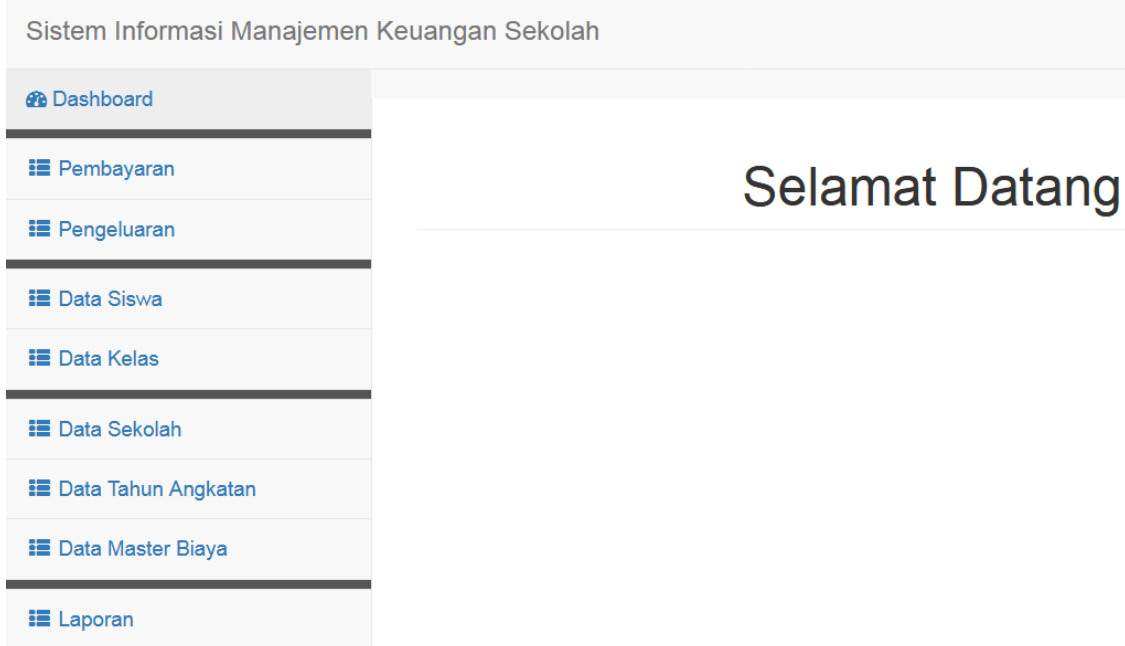

$2 \operatorname{admin}=\Leftrightarrow$ Logout

Gambar 8. MENU UTAMA/DASHBOARD

Di menu pembayaran di kolom aksi ada tombol print yang akan langsung mengambil atau mendownload data pembayaran siswa berbentuk kwitansi berformat pdf. Informasi yang ditampilkan dalam kwitansi tersebut adalah nama jenis pembayaran, nama siswa, nis siswa, kelas, tahun ajaran, nominal biaya, bulan pembayaran spp jika yang dibayarkan spp, dan tanggal pembayaran. Hal ini dapat dilihat pada Gambar 9 dibawah ini.

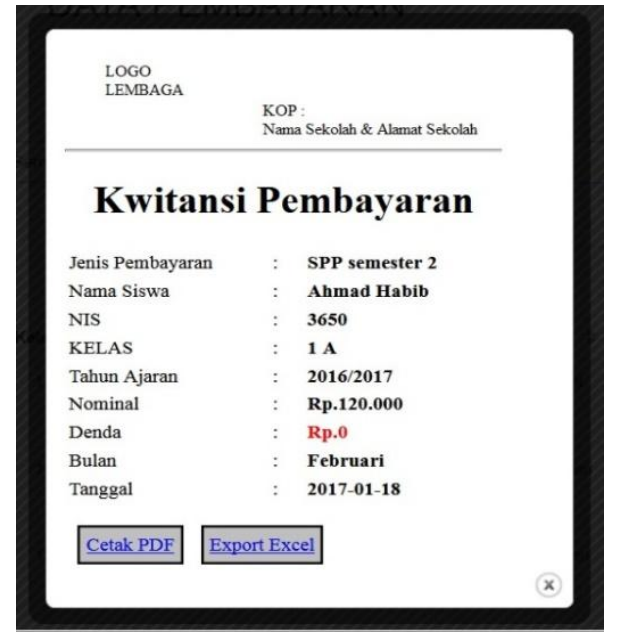

Gambar 9. TAMPILAN KWITANSI PEMBAYARAN

Pengujian pada sistem informasi manajamen keuangan sekolah ini menggunakan metode black box. Berikut ini adalah hasil pengujiannya dari segi penggunaan admin. Dapat dilihat pada tabel 1 berikut : 
INTENSIF, Vol.2 No.2 August 2018

ISSN: 2580-409X (Print) / 2549-6824 (Online)

Website: http//ojs.unpkediri.ac.id/index.php/intensif

Tabel 1. HASIL PENGUJIAN PENGgUNAAN Sistem PADA ADMIN

\begin{tabular}{|c|c|c|c|}
\hline No. & 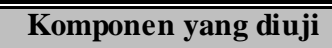 & Skenario butir uji & $\overline{\text { Hasil pengujian }}$ \\
\hline 1. & Menu Login & Login ke sistem admin & - Berhasil \\
\hline 2. & Menu Utama/dashboard & $\begin{array}{l}\text { Menampilkan halaman menu } \\
\text { utama/dashboard dan menampilakan } \\
\text { "Selamat Datang" serta daftar menu } \\
\text { ut ama secara lengkap }\end{array}$ & $\begin{array}{l}\text { - Berhasil } \\
\text { - Fidak Berhasil }\end{array}$ \\
\hline 3. & Menu Pembay aran & $\begin{array}{l}\text { Menampilkan daft ar pembayaran, } \\
\text { menambah, merubah dan menghapus } \\
\text { data pembayaran sertacet ak kwitansi } \\
\text { pembayaran, pencarian cepat data } \\
\text { pembayaran berdasarkan NIS(nomor } \\
\text { induk siswa) }\end{array}$ & $\begin{array}{l}\text { - Berhasil } \\
\text { - Fidak Berhasil }\end{array}$ \\
\hline 4. & Menu Pengeluaran & $\begin{array}{l}\text { Menampilkan daft ar pengeluaran, } \\
\text { menambah, merubah, menghapus, } \\
\text { mencetak, pencarian cepat berdasarkan } \\
\text { data nama pengeluaran }\end{array}$ & - Berhasil \\
\hline 5. & Menu Data Siswa & $\begin{array}{l}\text { Menampilkan, menambah, merubah, } \\
\text { menghapus, pencarian cepat dan detail } \\
\text { data profil siswa serta detail data } \\
\text { pembayaran SPP dan semua } \\
\text { pembayaran lainnya }\end{array}$ & - Berhasil \\
\hline 6. & Menu Data Kelas & $\begin{array}{l}\text { Menampilkan daft ar kelas, menambah, } \\
\text { merubah dan menghapus sert a pencarian } \\
\text { cepat data kelas }\end{array}$ & - Berhasil \\
\hline 7. & Menu Data Sekolah & $\begin{array}{l}\text { Menampilkan, merubah data sekolah } \\
\text { terkait nama sekolah, nama kepala } \\
\text { sekolah, alamat, nomor telpon, email } \\
\text { serta data sekolah lainnya }\end{array}$ & - Berhasil \\
\hline 8. & $\begin{array}{l}\text { Menu Data Tahun } \\
\text { Angkatan }\end{array}$ & $\begin{array}{l}\text { Menampilkan daft ar angkatan, } \\
\text { menambah, merubah serta pencarian } \\
\text { cepat data tahun angkatan }\end{array}$ & - Berhasil \\
\hline 9. & Menu Data Master Biaya & $\begin{array}{l}\text { Menampilkan daftar master biaya, } \\
\text { menambah, merubah, serta pencarian } \\
\text { cepat data master biaya }\end{array}$ & - Berhasil \\
\hline 10. & Menu Laporan & $\begin{array}{l}\text { Menampilkan laporan pembayaran dan } \\
\text { laporan pengeluaran serta bisa di export } \\
\text { ke file excel dan juga bisa di cetak ke } \\
\text { printer }\end{array}$ & $\begin{array}{l}\text { - Berhasil } \\
\text { - FidakBerhasil }\end{array}$ \\
\hline
\end{tabular}


INTENSIF, Vol.2 No.2 August 2018

ISSN: 2580-409X (Print) / 2549-6824 (Online)

Website: http://ojs.unpkediri.ac.id/index.php/intensif

Berikut ini adalah hasil pengujian sistem dengan 2 subjek berbeda. Dapat dilihat pada tabel 2 berikut:

Tabel 2. Hasil Pengujian Penggunaan Sistem Oleh User dengan 2 Subjek Berbeda

\begin{tabular}{|c|c|c|c|c|}
\hline No. & User & $\begin{array}{c}\text { Spesifikasi Perangkat Keras } \\
\text { dan Lunak }\end{array}$ & Skenario uji coba & Hasil Pengujian \\
\hline 1. & $\begin{array}{l}\text { User } \\
\text { Pertama }\end{array}$ & $\begin{array}{l}\text { Hardware: Intel core } 2 \text { duo } 1.6 \\
\text { GHz, RAM } 2 \text { GB. } \\
\text { Software: Windows } 7 \text { Profesional } \\
32 \text { bit, Google Chromeversion } \\
55.0 .2883 .87 \text {. }\end{array}$ & $\begin{array}{l}\text { Membuka semua menu dan } \\
\text { melihat sistem berjalan } \\
\text { dengan baik dan sesuai } \\
\text { dengan fungsinya. }\end{array}$ & $\begin{array}{l}\text { Di dalam pengujian pada } \\
\text { user pertama sistem } \\
\text { berjalan lancar. }\end{array}$ \\
\hline 2 . & User Kedua & $\begin{array}{l}\text { Hardware: Intel core } 332.4 \mathrm{GHz} \text {, } \\
\text { RAM } 2 \mathrm{~GB} \text {. } \\
\text { Software: Windows } 8.164 \text { bit, } \\
\text { Mozilla Firefox version 50.1.0. }\end{array}$ & $\begin{array}{l}\text { Membuka semua } \text { теnu } \\
\text { dengan melihat sistem } \\
\text { berjalan dengan baik dan } \\
\text { sesuai dengan fungsinya. }\end{array}$ & $\begin{array}{l}\text { Di dalam pengujian pada } \\
\text { user kedua sistem } \\
\text { berjalan lancar dan } \\
\text { melakukan proses lebih } \\
\text { cepat dibandingkan } \\
\text { dengan } \text { user } \text { pertama. }\end{array}$ \\
\hline
\end{tabular}

\section{KESIMPULAN DAN SARAN}

Berdasarkan hasil analisa yang telah dilakukan selama proses rancang bangun sistem informasi manajemen keuangan sekolah, maka dapat diambil kesimpulan bahwa Sistem informasi manajemen keuangan sekolah ini dapat memberikan kemudahan dalam proses penginputan data pembayaran maupun pengeluaran, membantu mempercepat kinerja bagian keuangan, meningkatkan keakuratan dalam melakukan transaksi keuangan.

Penelitian lanjutan kami adalah sebuah anlisa untuk perbaikan dan peningkatan lebih lanjut agar sistem informasi manajemen keuangan sekolah ini bisa lebih optimal dan lebih menarik, yaitu dengan perbaikan tampilan agar ukuran tampilan dapat mengikuti ukuran layar pada smartphone. Desain aplikasi kurang maksimal dari segi tampilan, oleh karena itu desain aplikasi akan lebih menarik sehingga lebih mempunyai daya tarik tersendiri bagi user.

\section{UCAPAN TERIMAKASIH}

Penulis mengucapkan terima kasih kepada Direktorat Riset dan Pengabdian Masyarakat Direktorat Jenderal Penguatan Riset dan Pengembangan Kementerian Riset, Teknologi dan Pendidikan Tinggi Sesuai dengan Kontrak Penelitian Tahun Anggaran 2018 yang telah memberi dukungan financial terhadap penelitian ini. 


\section{DAFTAR PUSTAKA}

[1] Cheng Xie; Po Yang; Yun Yang, "Open Knowledge Accessing Method in IoT-Based Hospital Information System for Medical Record Enrichment,” IEEE Access, vol. 6, pp. 15202 - 15211, 2018.

[2] Batya Friedman ; Lisa P. Nathan ; Daisy Yoo, "Multi-Lifespan Information System Design in Support of Transitional Justice: Evolving Situated Design Principles for the Long(er) Term," Interacting with Computers, vol. 29, no. 1, pp. 80-96, 2017.

[3] Lina García-Cabrera; Nuria Medina-Medina; Pedro J. Sánchez; Luis Martínez, "An axiomatic approach to maintaining the consistency of a hypermedia information system based on the SEM-HP model," Logic Journal of the IGPL, vol. 22, no. 6, pp. 1045-1074, 2014.

[4] Johan Casselgren; Ulf Bodin, "Reusable road condition information system for traffic safety and targeted maintenance," IET Intelligent Transport Systems, vol. 11, no. 4, pp. 230-238, 2017.

[5] Kimberlee J. Kearfott; Zachary D. Whetstone; Khwaja M. Rafique Mir, "Use of a geographic information system (GIS) for targeting radon screening programs in South Dakota," Journal of Radiation Research, vol. 57, no. 1, pp. 84-90, 2016.

[6] Yanli Liu; Dongxu Lu; Liangchen Deng; Tianyuan Bai; Kai Hou; Yuan Zeng, "Risk assessment for the cascading failure of electric cyber-physical system considering multiple information factors," IET Cyber-Physical Systems: Theory \& Applications, vol. 2, no. 4, pp. 155-160, 2017.

[7] Zhiting Song; Yanming Sun; Hehua Yan; Dingjuan Wu; Peng Niu; Xiangmiao Wu, "Robustness of Smart Manufacturing Information Systems under Conditions of Resource Failure: A Complex Network Perspective," IEEE Access, vol. 6, pp. 3731-3738, 2018.

[8] Andrej Dobrovoljc; Denis Trček; Borut Likar, "Predicting Exploitations of Information Systems Vulnerabilities Through Attackers' Characteristics,” IEEE Access, vol. 5, pp. 26063-26075, 2017.

[9] Marcelo Zambrano; Israel Perez; Federico Carvajal; Manuel Esteve; Carlos Palau, "Command and Control Information Systems applied to Large Forest Fires Response," IEEE Latin America Transactions, vol. 15, no. 9, pp. 1735 - 1741, 2017.

[10] Claude Aynaud; Coralie Bernay-Angeletti; Romuald Aufrere; Laurent Lequievre; Christophe Debain; Roland Chapuis, "Real-Time Multisensor Vehicle Localization: A Geographical Information System?Based Approach," IEEE Robotics \& Automation Magazine, vol. 24, no. 3, pp. 65-74, 2017.

[11] Santanu Chatterjee; Sandip Roy; Ashok Kumar Das; Samiran Chattopadhyay; Neeraj Kumar; Alavalapati Goutham Reddy; Kisung Park; Youngho Park, "On the Dresign of fine Grained Access Control With User Authentication C=Scheme for Telecar," IEEE Access, vol. 5, pp. 7012-7030, 2017.

[12] M. Jaya Bharata Reddy; Rounak Meyur; Diptak Pal; C. Krantikumar; D. K. Mohanta, “An on -line geographical information system-based condition monitoring system for 11-kv distribution line insulator," IEEE Electrical Insulation Magazine, vol. 33, no. 3, pp. 26-32, 2017.

[13] Runtong Zhang; Donghua Chen; Xiaopu Shang; Xiaomin Zhu; Kecheng Liu, "A KnowledgeConstrained Access Control Model for Protecting Patient Privacy in Hospital Information Systems," IEEE Journal of Biomedical and Health Informatics, vol. 22, no. 3, pp. 904-911, 2018.

[14] Antonio Celesti; Maria Fazio; Agata Romano; Alessia Bramanti; Placido Bramanti; Massimo Villari, "An OAIS-Based Hospital Information System on the Cloud: Analysis of a NoSQL ColumnOriented Approach," IEEE Journal of Biomedical and Health Informatics, vol. 22, no. 3, pp. 912918, 2018.

[15] Hu Xiong; Junyi Tao; Chen Yuan, "Enabling Telecare Medical Information System With String Authentication and Anonymity," IEEE Access, vol. 5, pp. 5648-5661, 2017.

[16] Mariagrazia Dotoli; Hayfa Zgaya; Carmine Russo; Slim Hammadi, "A Multi-Agent Advanced Traveler Information System for Optimal Trip Planning in a Co-Modal Framework," IEEE Transactions on Intelligent Transportation Systems, vol. 18, no. 9, pp. 2397-2412, 2017.

[17] Jing Fan; Li Gao; Jinping Gao, "Study on the diffusion performance of standard e-government information systems," China Communications, vol. 13, no. 5, pp. 182-202, 2016. 